\title{
Tackling Africa's Scientific and Technological Underdevelopment: The Role of the Humanities
}

\author{
Gamel Nasser Adam \\ Senior Lecturer, Department of Modern Languages (Russian Section), \\ University of Ghana, Legon, Ghana
}

\begin{abstract}
One major factor responsible for Africa's underdevelopment is the continent's weak scientific and technological capacity. Policy makers have subsequently been focusing on the natural sciences with perfunctory attention being accorded the humanities. Even the academy in Africa reflects this trend. This paper argues for commensurate emphasis to be placed on the capacity of the humanities in order to nurture thinkers and to cultivate the relevant consciousness to counter the complexes that negatively impact the confidence of the African people relative to their capability to create a robust scientific and technological culture.
\end{abstract}

Keywords: science and technology, humanities, development, Africa, history

Evidence abounds, as the example of Africa clearly confirms, that the availability of vast amounts of natural resources is not conterminous with a successful socio-economic transformation. Indeed, despite its abundant natural wealth, Africa still harbours twenty-five of the thirty poorest countries in the world, with sub-Saharan Africa accounting for thirty-three of the forty-eight of the world's least developed countries according to data from the United Nations Committee for Development Policy (May, 2016). Clearly, to rectify this paradox of a continent basking in wealth and its citizens wallowing in poverty would require the mastery of science and technology to convert this mineral wealth into tangible goods and commodities that would positively impact the general quality of life of the masses of the 
people. In other words, Africa would have to embark on a robust and aggressive science and technology programme in which policy makers, the comity of universities and research institutions would work in focused partnership. In this partnership, priority attention should be on the study of the basic and applied sciences targeting the relevant technologies and innovations that could be applied to indigenous industry and the overall production processes.

While this appears to be the most logical action programme under the prevailing circumstances, it is important to stress the point that this envisaged revolution in science and technology cannot happen in a vacuum. There has to be a commensurate socio-cultural climate and the requisite national consciousness to propel the new dynamics and to usher in the new order. With relevant references to history, classics and literature this paper demonstrates the critical importance of the humanities in creating the overall background environment that would enable a science and technology culture to flourish in Africa.

\section{The Intrinsic and Practical Values of the Humanities: Restating the Main Arguments}

This paper proceeds from the argument that using the humanities as an instrument to promote a science and technology culture reinforces their intrinsic as well as their practical value. Fitzgerald (2014) affirms the importance of the study of the humanities among scientists and technologists by citing the example of the curriculum of the Massachusetts Institute of Technology (MIT), one of the world's leading research universities in science, technology, engineering and mathematics (p. 1). Apart from their core studies in advanced technical knowledge and skills, students at MIT are also required to spend some time studying literature, languages, music and history. In these classes, students

learn how individuals, organizations, and nations act on their desires and concerns. They gain historical and cultural 
perspectives, and critical thinking skills that help them collaborate with people across the globe, as well as communication skills that enable them to listen, explain, and inspire. They learn that most human situations defy a single correct answer, that life itself is rarely, if ever, as precise as a math problem, as clear as an elegant equation. (p. 11)

In other words, the MIT views 'the humanities, arts, and social sciences as essential, both for educating great engineers and scientists, and for sustaining ... capacity for innovation' (p. 11).

In addition to the argument above, it is important to stress that humanists are in the forefront in all academic and related endeavours, encouraging critical and analytical thinking as important ingredients for a functioning, cohesive and stable society. The study of other languages and cultures, for example, contributes in preparing the student to fit into a global community. In a robust response to the growing tendency among policy makers and sections of the academic community to deprioritise the humanities, the American Academy of Arts and Sciences published a report in 2013 titled The heart of the matter. The said report restated the inherent essence of the humanities, arguing that 'the humanities remind us of where we have been and help us envision where we are going. Emphasizing critical perspective and imaginative response, the humanities ... foster creativity, appreciation of our communalities and our differences, and knowledge of all kinds' (p. 11). In its comments on the possibilities and promise of the humanities, another 2013 report of a working group of Harvard College contends that:

Education in the traditional humanistic disciplines that engage philosophical, historical, literary, and artistic works, or that teach students how to write and talk persuasively about such works ... can be the scourge of a culture or its greatest hope. Both dangerous and at the same time potentially liberating or redemptive, the humanities can help to clarify one's sense of purpose or to undermine it, can help 
to identify possibilities for greatness in a culture or can artfully destabilize an existing world. An understanding of the power of the humanistic enterprise, therefore, and an understanding of how responsibly to engage it and employ it, should be central aims of any education in the humanities. (p. 40)

The 2013 report of the American Academy of Arts and Sciences, alluded to earlier, further identifies three goals which, though specific to the United States, nevertheless have resonance in other socio-cultural settings. The first of the three goals is to educate students in 'the knowledge, skills, and understanding they will need to thrive in a twenty-first century democracy'. The second is 'to foster a society that is innovative, competitive and strong', and the third is 'to equip the nation for leadership in an interconnected world'. The report is emphatic in its conclusion that 'these goals cannot be achieved by science alone' (p. 8).

Humanists in Africa have also been drawing attention to the need to prioritise the humanities in the continental development agenda. The Forum on the Humanities in Africa of the African Humanities Program (2014) has voiced concern over how policy makers and even sections of the academia have deprioritised the humanities. It makes a case for this trend to be reversed arguing that 'no knowledge-led development strategy can succeed without a solid core of humanistic understanding and humane values' (p. 3). It further reiterates the practical value of the humanistic sciences, especially their ability to encourage creative, analytical and critical thinking, and also to nurture a questing and questioning spirit. In consequence of these arguments, it makes recommendations to national and higher education policymakers, specifically stressing the need to "value the concrete contributions of history, languages, culture, and the arts, and other humanities disciplines as an essential component of a comprehensive system of higher education for the betterment of the nation and continent' (p. 3). It also asks policy makers to 
'actively encourage participation in national policy debates by humanities scholars, along with those in other disciplines' (p. 3)

Pablo (2007) contends that 'it requires that the humanities, besides continuing to do what they have done very well for millennia-interpret the past, imagine the future, explore the possible, test and enrich the present-, also insert themselves in the real-world ...'(p. 174).

Shula (2000) also argues:

We cannot afford not to be concerned with the humanities, for it is in the humanities, more than anywhere else, where we are able to think alternatives, to ponder on where we have come from and where we are going, that we come to reflect on what it means to be human; where - in the words of Coetzee and Bunting, we learn 'to deal with and manipulate different cultural symbols, operate indiverse social settings and develop complex notions of identity and citizenship'. (p. 227)

Falola (2012) extends the argument further by stating that 'creating, managing, and solving underdevelopment is largely a human concern. And this is precisely where the humanities come to the fore as they generate greater imagination, thereby creating more intellectual stimulation and creativity, encouraging broader reflection on the future of society' (p. 32).

These arguments in defence of the humanities confirm not only the intrinsic value of the related disciplines, but equally importantly, they reassert their inherent potential to impact practically the efforts at transforming society. Anchored on the fundamental thrusts of these arguments, this paper goes further to place special emphasis on the capacity of the humanities to contribute to the mobilisation of national and continental effort directed at tackling Africa's crisis of underdevelopment, with particular reference to the continent's quest for scientific and technological transformation. 


\section{The Disconnect between Awareness and Commitment: A Brief Evaluation of the Political Responses to Science and Technology in Africa}

Without exception, African political leadership has over the years been stressing the need to pay greater attention to science and technology. Research institutions, and in some cases separate ministries, have been created devoted solely to matters relating to science, technology and research. Educational institutions have also been urged to give priority attention to science education. At the Pan-African level, the centrality of science and technology to the continent's development is probably best illustrated, albeit symbolically, by the setting aside of $30^{\text {th }}$ June as the continent's science and technology day by the then Organisation of African Unity. This is to enable the focusing of attention on the need to accord science and technology the necessary seriousness, recognising their importance in the continent's struggle to liquidate underdevelopment and its associated inimical effects on the citizenry.

In more concrete terms, the urgency of embracing science and technology has continually been stressed in various PanAfrican concept documents such as the Lagos Plan of Action of 1980, the Kilimanjaro Declaration of 1987 and the Addis Ababa Declaration of 1988. The Lagos Plan of Action of 1980, in particular, stated in its preamble the commitment of member states to 'put science and technology in the service of development by reinforcing the autonomous capacity of our countries in this field' (p.4). Member states were thus urged to:

adopt measures to ensure the development of an adequate science and technology base and the appropriate application of science and technology in spear-heading development in agriculture; transport and communications; industry, including agro-allied industries; health and sanitation; energy, education and manpower development, housing, urban development and environment. (p. 34) 
Unfortunately, much of the African political response to this problem has not gone beyond statements of commitment and the creation of largely superficial administrative structures. In other words, the gravity of the situation does not seem to elicit the corresponding levels of urgency on the part of the African political leadership to match rhetoric with concrete and practical action. For example, of the fourteen stated objectives of the African Union, the promotion of science and technology is in the thirteenth position. And despite the provision in the Lagos Plan of Action which urged member states to ensure that by 1990 they would have mobilised one percent of their GDP for the development of their scientific and technological capabilities, hardly any member state has thus far met this target.

This is in spite of the fact that countries with similar problems in the past, but which have managed to break out of the cocoon of industrial stagnation, have all accorded science and technology priority attention in terms of allocation of resources. This is especially so with regard to the Newly Industrialised Countries (NICs), such as Hong Kong, Singapore, South Korea and Taiwan. For example, concerning the national expenditures on Research and Development and the number of researchers per a million inhabitants, Ogbu (2004) points out that 'the NICs spend US \$66 per inhabitant while China spends \$17, India \$11 and Africa \$6. Sub-Saharan Africa has 113 researchers per million population compared to China's 454, India's 151 and NICs' 595' (p. 2).

Clearly, such a casual approach to a science and technology agenda does not portend optimism for any successful resolution of the crisis of industrial stagnation. And to turn the continent's fortunes around would require the mobilisation of the best of Africa's minds including those that are better equipped with the relevant knowledge about the experiences in history, and how to apply those experiences to African contemporary exigencies. 


\section{Complementing Scientific Revolution with the Cultivation of the Right Background Consciousness through the Humanities}

The argument has been made that African political leadership and policy shapers rightly perceive the natural sciences and the technologies that flow from them as not only critical to national development, but also a fundamental determinant of economic progress and national productive capacity and output. A 1992 report of a presidential committee which was tasked to review Ghana's education reforms made the following argument.

A key to the future socio-economic development of Ghana lies in the development of science and technology education. Ghana has growing need for a large number of scientists, engineers and technicians to bring about technological innovation required for her development and for future development of science and technology. With the doubling of science and technology knowledge and its pervading effect on every aspect of life, it has become very urgent for all citizens to be literate in science to enable them to understand and utilise science and technology. (p. 214215)

With particular reference to the curricula of universities and analogous institutions, the report further states:

Tertiary institutions are mandated, inter alia, to emphasise programmes that are of special relevance to national development. In general, every programme is relevant in the context of total national development. Some courses may be more critical than others to national development priorities and human resource needs at different points in time. Such courses will need greater attention in terms of emphasis and funding. For the current needs of the country, science, technology and ICT should be emphasised in the curriculum of tertiary institutions. (p. 122) 
On its part, The University of Ghana Strategic Plan 20142024 provides further illustration of this tilting focus towards the sciences. Of the nine priority areas of the said Strategic Plan, research is listed as the first, and with special emphasis placed on the natural sciences. This prioritisation is anchored on the argument that 'the application of new technologies drawn from evidence-based research in areas such as agriculture and manufacturing has transformed many economies' (p. 12). The role of the other disciplines outside the domain of the natural sciences is captured in the second priority area under 'Teaching and Learning' where concepts, such as 'leadership development' and 'thought leaders' are mentioned.

In emphasising the urgency of giving priority to the creation of the requisite science and technology infrastructure, the Lagos Plan of Action laments the 'ineffective linkage pattern of research and development and national production activity, in particular the persistent orientation towards research of general interest and free knowledge' (p. 36). If the meaning of what the Plan of Action refers to as 'research of general interest and free knowledge' is stretched far enough, the inevitable conclusion is that the disciplines in the humanities, more than any other, are those that are being alluded to. While not denying the pivotal role of science and technology in this endeavour, it is important to stress that in the collective drive to mobilise national brainpower for the pursuit of socio-economic and technological transformation, the humanities, far from merely being preoccupied with knowledge of general interest or with the pursuit of knowledge for its own sake, could offer practical responses to pressing societal challenges.

In the last few decades, for example, the synergy among the three great revolutions in quantum mechanics, computer and bio-technology has unleashed a tidal wave of scientific discoveries enabling scientists to increasingly acquire almost God-like attributes of manipulating nature almost at will. The bio-molecular revolution, for instance, has opened up possibilities to grow human organs in test tubes. There are further possibilities of 
reengineering the genetic code, including the human one, in order to produce made-to-order living things. These possibilities open up very profound challenges which the implicated scientific disciplines cannot handle. If, for example, these advances in science succeed in increasing life expectancy exponentially to an average of two hundred years and more, then some fundamentals of the understanding of time by humans, anchored on current paradigms, will have to change. The concept of youth and old age will also have to be redefined. Even more critically, humankind will have to figure out what to do with the extra time associated with the extended longevity of life, and the corresponding Malthusian intricacies that may arise.

Added to these complications is the exponential growth in material comfort that comes with the practical applications of science and technology, and the gross inequalities between the techno-haves and the techno-have-nots that this would engender. This extended techno-divide would mean that inequalities would grow to the point of extreme obscenity, where a small fraction of the world's population would appropriate almost all the benefits of these scientific advances, while the majority populations in other areas would continue to lack the most basic means of survival, such as potable water. Even more profound will be the further complications with inequalities if the techno-haves, who are already highly advanced economically, tear further away from the rest of the global pack by further enhancing their mental abilities through the genetic engineering of super intelligent brains. These are challenges that require contemplation and reflection in order to prevent, or to provide the necessary antidotes against the consequences emanating from a collision between science and the self-destructive impulses of humankind. These anticipated challenges would require the critical intervention of humanists. 


\section{The Humanities and the Creation of the Relevant Background Consciousness}

The successful consolidation of a science and technology culture in Africa will be contingent upon the nature of the background social environment and the consciousness that goes with it. In other words, it is important not to lose sight of the critical importance of the background environment necessary to create the requisite consciousness amenable to a science and technology culture. Marx (1977) argues that it is not the consciousness of men that determines their being, but, on the contrary, their social being that determines their consciousness.' ( $p$. 131). And the social being is set within the context of a concrete material mode of production which, when it changes also engenders a corresponding change in the level of consciousness. For example, the feudal mode of production would have a corresponding level of social consciousness specific to that mode of production, just as capitalism would also have its associated level of consciousness specific to it. Under conditions of neo-colonial dependency there is a corresponding neo-colonial consciousness, the consequence of which is an obfuscation of the awareness among the captive populations of the real causes of their overall underdevelopment and what they can do to alter the status quo.

In Africa, the more-than four centuries of slavery which effectively reduced the African people to the status of sub-humans, colonial rule of over a century and the several decades of neocolonial domination have all combined to create and sustain a consciousness inherently deleterious to the aspirations of the African people for socio-economic emancipation. While slavery largely fed on the racist premise that the African was subhuman, colonialism placed emphasis on what it deemed the benightedness of the African people who needed to be civilised. The overall subliminal effect of these racist prejudices is the creation of a system of complexes which has ingrained itself in the collective consciousness of Africans, making many of them to accept the view that they are an inferior people. Their superficial understanding of the realities of the world around them tends to reinforce these complexes. All 
around, there is the ubiquitous presence of the marvels of technological achievements, including the airplanes, space exploration, computers, mobile phones and the biotechnological revolution. In all these developments driven by the human genius, it seems Africa is a mere bystander.

Against the background of the overall failure to mount a robust counter-offensive against these prejudices, the narrative about the African milieu not being capable of matching the levels of socio-economic and cultural development of the advanced industrialised countries has tended to aggravate an already precarious situation. Even more debilitating is the fact that the protest voices of those who reject this thesis about the racially determined techno-divide as unscientific, are most often drowned by what seems at face value to be evidence in support of this hegemonic theory.

The response, therefore, should be the deliberate cultivation of a counter-consciousness to challenge this dominant stereotype. This can be done by mobilising all the instruments available in the art of mental programming with the objective of boosting the requisite confidence in the African people about their capabilities. Aspects of this mental programming could be taken up by specific disciplines in the humanities.

\section{Restoring Optimism through History and the African Technological Heritage}

The consciousness of a people and especially the awareness of their history are proportional to their ability to understand and make sense of the moment and of contemporary exigencies. Therefore, history, or the people's awareness of their heritage, is an important instrument in the battle to create the right type of consciousness commensurate with the demands of the time, especially with regard to restoring their self-esteem and confidence in themselves and their capabilities. According to Sweeting and Edmond (1989), 
Heritage ... is how a people have used their talent to create a history that gives them memories that they can respect, and use to command the respect of other people. The ultimate purpose of heritage, and heritage teaching, is to use a people's talent to develop an awareness and a pride in themselves so that they can become a better instrument for living together with other people. (p. 5)

Aspects of the despondency associated with the narrative about Africa's perceived technological inabilities could be tackled by emphasising the historical dimension of the problem. Students of African history, especially the history told by Africans themselves, will know that this techno divide has not always been like that throughout history. Franklin (1947) argues that 'the blacks from Nubia had helped to construct the great sphinxes, pyramids, and public buildings of Egypt. They had helped to perfect the political organization of the country' (p. 8). Indeed 'as early as 2000 B.C.,' Foster (1954) says, 'the Negro Ra Nahesi sat upon the Egyptian throne' (p. 16). Diop (1974) argues that the name by which the Ancient Egyptians called their country was Kemit, which meant 'black' in the language they spoke. 'The interpretation according to which Kemit designates the black soil of Egypt, rather than the black man and, by extension, the black race of the country of the Blacks, stems from gratuitous distortion by minds aware of what an exact interpretation of this word would imply (p. 7). Herodotus, the Fifth Century B.C. Greek historian known as 'the Father of History' confirms that 'the Egyptians of his time had dark skins and woolly hair' (Foster, 1954, p. 17). Du Bois (1947), for his part, asserts: 'We conclude, therefore, that the Egyptians were Negroid and not only that, but by tradition they believed themselves descended not from the whites or the yellows, but from the black peoples of the South' (p. 106).

Obenga (1973) makes similar arguments. But perhaps the most incontrovertible evidence of Ancient Egypt being black African is provided by the scientific testing of skin pigmentation. 
Commenting on a paper presented by Cheikh Anta Diop at a 1974 UNESCO conference in Cairo, Nabudere (2007) writes:

Diop reported that he had succeeded in developing a melanin dosage test which was scientifically able to determine the skin colour of the ancient Egyptians. What he required for testing, of course, were the skin remains of the ancient Egyptians. Because of the hostility and obstructive behaviour of the Egyptian bureaucracy guarding the museums, Diop encountered great difficulty in testing the mummies. Yet even with the small samples that he was able to obtain, he demonstrated conclusively that Ramses I had been a black Pharaoh. (p. 16).

Even after it had been ruined by successive invasions, Egypt, which had been the cradle of civilisation for ten thousand years, long continued 'to initiate the younger Mediterranean peoples (Greeks and Romans, among others) into the enlightenment of civilization. Throughout Antiquity it would remain the classic land where the Mediterranean peoples went on pilgrimage to drink at the fount of scientific, religious, moral, and social knowledge, the most ancient such knowledge that mankind had acquired.' (Diop, 1974, p. 10)

Nkrumah (1973) also makes an incursion into history to demonstrate Africa's glorious past, with specific reference to the ancient Ghana Empire. He argues that:

long before England had assumed any importance, long even before her people had united into a nation, our ancestors had attained a great empire ... which stretched from Timbuktu to Bamako, and even as far as to the Atlantic. It is said that lawyers and scholars were much respected in that empire and that the inhabitants of Ghana wore garments of wool, cotton, silk and velvet. (pp. 107108)

If the African people of yonder years could achieve such pioneering feats of sophistication, what then is responsible for 
Africa's retardation in almost every sphere of human progress today? History, once again, provides the answer. After several millennia of existence, the ancient Egyptians drifted further into the interior of the continent where they settled to form the embryos of future African empires. Separated by long periods of isolation and enormous distances, the emergent empires were practically severed from the cradle of civilization, whence they originated. This situation was made worse by foreign invasions of Egypt and the latter's subsequent decline. The geography and the general environment of their new habitat in the interior of the continent impinged negatively on the scientific creativity of the migrant people from Kemit. According to Diop (1974),

"Adaptation to the narrow, fertile Nile Valley required expert technique in irrigation and dams, precise calculations to foresee the inundations of the Nile and to deduce their economic and social consequences.It also required the invention of geometry to delimit property after the floods obliterated boundary lines. By the same token, the terrain in long flat strips required the transformation of the paleoNegritic hoe into a plow, first drawn by men, subsequently by animals. Indispensable as all that was for the Negro's material existence in the Nile Valley, it became equally superfluous in the new living conditions in the interior. With economic resources assured by means that did not require perpetual inventions, the Negro became progressively indifferent to material progress. It was under these new conditions that the encounter with Europe took place". (p. 23)

This encounter with Europe further exacerbated the postKemit crisis of the African people, and one clear consequence of this is the collective amnesia among Africans in relation to their past civilisational, organisational and technological efflorescence. The attendant 'climate of alienation', Diop (1974) argues, 'finally deeply affected the personality of the Negro, especially the educated Black who had had an opportunity to become conscious 
of world opinion about him and his people.' (p. 25). Diop further laments that such historical rootlessness makes the educated Black lose 'confidence in his own possibilities and in those of his race', and this is to such an extent that despite the validity of the evidence he, Diop, has consistently presented about the black African origins of ancient Egyptian civilization, 'it will not be astonishing if some of us are still unable to believe that Blacks really played the earliest civilizing role in the world' (p. 25).

Another consequence of the African encounter with Europe was the instance where the Industrial Revolution of the late eighteenth century passed Africa by, but flourished in Europe. A very important factor which accounted for this missed opportunity was the Trans-Atlantic Slave Trade, which was a direct offshoot of the European encounter. The four centuries of slavery not only depleted the continent of a critical segment of its most mentally and physically productive population, but also ensured that the pervasive chaos and instability of the period did not allow for the smooth-flowing development continuum of society. This normally should allow one generation to transmit to another the achievements of its labour and other endeavours in the process of harnessing nature and the environment. The attendant chaos and instability associated with the slave raids and the constant movements of whole populations in panic exodus to escape or avoid such raids, all combined to prevent the Industrial Revolution from diffusing into Africa.

Further to the argument above, it is also important to emphasise the point that despite the traumatic legacy of slavery African Americans especially, have made spectacular contributions to the early and contemporary scientific and technological development of the United States of America, and the history of America's industrial and technological transformation, for example, would not be complete without the notable contributions of engineers and scientists of African descent. Forster (1954) confirms this: 
In the world of invention and science the Negro has come rapidly to the fore. Negroes are credited with nearly 5,000 patents... They have produced a number of well-known scientists, especially in the fields of biology, chemistry and medicine. The most outstanding of these scholars were E. E. Just and the world-renowned George Washington Carver. The latter genius made fundamental industrial and agricultural researches into the potentialities of the sweet potato, peanut, and other agricultural products, which have added vastly to the wealth of the South. President Truman proclaimed January 5, 1946, as George Washington Carver Day, and a new three-cent stamp was issued in his honor. (p. 514)

At the outbreak of the Second World War, the United States of America recruited the best of the world's most renowned physicists to develop the atom bomb under the Manhattan Project led by J. Robert Oppenheimer. In this elite group of geniuses were twelve African American scientists, notable among whom were Lloyd Quarterman, Earnest Wilkens and William Knox. Quarterman was later to be 'specifically honored by the U.S. Secretary of War for "work essential to the production of the Atomic Bomb, thereby contributing to the successful conclusion to World War II"' (Malerbo, 2005, p. 26).

These feats and moments of African scientific and technological ingenuity have to be disseminated among the masses of the African people in a most robust manner, and across the entire curriculum of the educational system. Though onerous, this responsibility should be shouldered by Africa's historians, anthropologists, political scientists, literary figures and other related academics. They have to endeavour to carry the masses of the people along in a concerted effort to combat the climate of resignation and despondency which negatively affects the selfconfidence of the African people. This self-confidence has been especially undermined because there is a missing link in the African people's collective understanding and appreciation of their history. This missing link blurs the relationship between cause and 
effect relative to the continent's underdevelopment. And when the link between cause and effect is missing or blurred, the victims are left bewildered or resigned to the prevailing status quo partly because they lack the vital tools or background knowledge that would enable them to make sense of the moment.

In other words, knowledge of these historical antecedents should help in creating the alternative consciousness which should convince the generality of Africans that the present scientific and technological underachievement is not embedded in the DNA of the African, but rather, it is a result of the peculiar circumstances of Africa's history. This fact, as well as some very critical questions whose answers lie outside the purview of the natural sciences, needs to be addressed in tandem with any surge in Africa's scientific and technological renaissance.

\section{Africa's Technological Retardation: Perspectives from the Classics}

Classical Greek history and civilisation offer some very insightful and analogous perspectives, relative to Africa with regard to the asymmetry between available talent and the lack of technological advancements. For example, it is a puzzling tinge of irony that some of the important technological inventions of the early eighteenth century Industrial Revolution did not happen a couple of millennia earlier in ancient Greece which was famous for its impressive stock of astute thinkers endowed with extraordinary mental prowess, such as Pythagoras, Euclid, Archimedes.

The explanation for this lies partly in the social structure of society as well as the prevalent mode of production, and the technology associated with it. Under the slave mode of production, for example, the majority slave population was compelled, by the use of routine force, to provide for the comfort and indulgence of the upper class of slave masters. This means that many technical minds may well have conceived modules of certain machines, but there probably would not have been any 
need for them at the time, nor the incentive to produce them. According to Larseñ (1977),

The Greek philosophers, studying and analysing all aspects of life, hardly ever questioned this state of affairs. It was generally accepted as the 'natural' or 'normal' condition of a large part of mankind that they must toil for the few. Therefore, a shortage of 'labour' or 'energy' in our modern sense was never a problem - when a job had to be done, the slaves just had to do it, and if they found it strenuous they were whipped until it was done. Human effort, life, or health was regarded as expendable as long as only the slaves were concerned. Why, then, should cultured and educated men rack their brains to invent labour-saving machines? (p. 20)

The irony of the incongruity between available talent and technological retardation also applies to the period up to the collapse of the Roman Empire generally referred to as the Middle Ages. Here too, the class structure of society played an equally decisive role. The class that appropriated the wealth from those who actually produced it, namely the class of peasants and craftsmen, condemning the latter to a life of penury, ensured that 'this concentration on the art of exploitation, rather than production, left them unaware of obvious deficiencies in production methods and devoid of the knowledge to effect improvements' (Lilley, 1977, p. 37). Similarly, such technical minds may have also existed among the slave population, but since they had no stake in the fortunes of the exploitative system, this probably stifled the relevant initiative. What all these mean is that under certain circumstances, the urge to innovate is stifled and development of technology stagnates in spite of the potential availability of the relevant skills or scientific minds. On the basis of the experiences of Roman and Greek antiquity alluded to above, there is ample evidence that contemporary African reality may be experiencing a similar phenomenon where there is clearly an asymmetry, just as in ancient Rome and Greece, between available talent and the continent's technological lethargy. 